\title{
EQUIPOS CON EMOCIÓN
}

\section{Joan Carles March Cerdá}

\section{Esc uela Andaluza de Salud Pública (Granada)} Email: tatesjoan@gmail.com

\section{EQUIPO, equipo, EQUIPO y +}

Hablar de equipos es para mí, hablar de 5 aspectos fundamentales.

1. El clima, el ambiente, las relaciones que hay en el equipo, que cuando existen de forma adecuada generan una SINERGIA de MANTENIMIENTO, importante para el funcionamiento de los equipos

2. EI RECONOCIMIENTO del SABER de las personas que conforman el equipo, ligado a lo que se da y lo que se recibe

3. La existencia de un proyecto conocido y compartido y a poder ser en el que las personas que forman parte de él, sienten que han participado en su definición

4. La COMUNICACIÓN existente entre las personas que forman parte del equipo

5. El LIDERAZGO, su estilo, su saber hacer, su qué y su cómo, sus capacidades y competencias, sus habilidades y actitudes

Y con la idea de estos 5 aspectos vamos a recorrerlos con la idea de conformar los equipos en los que nos gustaría estar y en los que NO 


\section{PARA EMPEZAR, como entremeses, NOS VAMOS AL CINE:}

Si es usted aficionado al cine recordará bien "Los intocables" de Brian de Palma, probablemente recordará una escena en la que De Niro-Al Capone se pone en pie, en una reunión de compinches pezzonovantes ("peces gordos") y pregunta a los reunidos si conocen lo que más le gusta al propio Capone. Las respuestas son chocarreras y tópicas: "iEl dinero!" "iLas mujeres!" "iEl alcohol!".

Capone niega con la cabeza, recoge un bate de béisbol que le entrega un subordinado y pronuncia un bello parlamento que hoy podrían reproducir (quizá lo hagan) los expertos en recursos humanos. Viene a decir: "No, lo que me gusta es el béisbol. El jugador está solo en la larga y azarosa jornada. Lanza, batea, corre, espera... lo hace solo pero forma parte de un equipo... es parte de un equipo y nunca debe olvidar al equipo...". Los subordinados asienten mientras saborean habanos. Las palabras del jefe han subrayado, por la vía de la metáfora deportiva, una obviedad técnicolaboral: la emoción es apenas un velo tenue en las palabras hasta que la metáfora levanta ese velo y el bate despeja todas las dudas de futuro de uno de los comensales. Es la emoción la que ha intervenido en el desenlace de un problema laboral. y necesitamos de la emoción como lubricante de la maquinaria de trabajo. 


\section{PRIMER PLATO: 2 películas más en esta sesión cinematográfica ligada al liderazgo.}

En estas dos películas podemos analizar y trabajar liderazgo, gestión de equipos, motivación y comunicación, entre otros aspectos

1. "Invictus"A través de la historia de Mandela, Clin Eastwood nos señala que si bien hay muchas formas de liderazgo, la más relevante es aquella que consigue seguidores capaces de hacer más de lo que creían posible. Para ello, el líder debe ser capaz de animar a las personas a creer en sí mismos para lograr el cambio más allá del horizonte tangible. Esto es lo que algunos teóricos definen como liderazgo transformacional, transformar a la sociedad desde su esencia. Mandela busca la integración, y a través de ella la reconciliación social. El rugby se convierte en el instrumento con el que puede comenzar a unir a un pueblo fuertemente dividido: unirlo en la esperanza de ganar la copa mundial o, "cómo nos inspiramos para la grandeza". Esta forma de liderazgo requiere la transformación real. El lider no sólo debe creer en la visión sino que debe comunicar esa visión en términos tangibles para que los demás vean esas posibilidades y estén dispuestos a actuar sobre ellas para el beneficio de todos. El mensaje es claro: Algo de esto falta en nuestros líderes actuales.

2. "300", Un equipo de verdad La actitud de "Leónidas" y sus $\mathbf{3 0 0}$ espartanos en la batalla de las Termópilas es un buen ejemplo de lo que un equipo cohesionado puede llegar a conseguir (especialmente en situaciones adversas). Una gran compañía en la que el líder y sus colaboradores se identifican y se comprometen con los valores de la misma (coraje, disciplina, honor, camaradería), una organización en la que todos sus profesionales son rigurosamente seleccionados, entrenados y desarrollados desde su incorporación a la misma.

Para defenderse de estas amenazas, el líder de la organización selecciona a su mejor equipo de profesionales y les encomienda llevar a cabo la difícil misión de asegurar la supervivencia de su compañía. Todos muestran un gran compromiso y lealtad. Y no 
dudan en exponerse a los riesgos de esta misión, confiando en todo momento en su líder y en el resto del equipo. No disponen de los mejores recursos y no están en igualdad de condiciones pero funcionan como un auténtico equipo: EL MEJOR.

$Y$ de esta compañía Esparta, podemos extraer algunas claves que les hace ser un EQUIPO DE VERDAD con

- Visión compartida,

- Enfoque

- Toma de decisiones

- Roles complementarios

- Diversidad del equipo

- Aprendizaje continuo

- Dinamismo del entorno.

La actitud de Leónidas y sus hombres en la batalla de las Termópilas es un buen ejemplo de lo que un equipo cohesionado puede llegar a conseguir (especialmente en situaciones adversas). Su éxito fue su mayor fuerza: EL TRABAJO EN EQUIPO_Y en esta película, destaca el discurso final, lleno de fuerza, motivación, ganas, pasión, interés por despertar el interés de los suyos, credibilidad,....... 


\section{SEGUNDO PLATO: Cine, cine, cine + CINE POR FAVOR, como diría Luís}

\section{Eduardo Aute: Sister Act, Eric}

\section{Brockovick y en Busca de la felicidad y}

\section{Gladiator}

1. Sister Act, me sirve para hablar de trabajo en equipo; para hablar de cómo intervenir en personas que, a mi juicio, deben mejorar su comportamiento, actitud o habilidades; para hablar de cómo hacer una crítica; para hablar de cómo abordar posibles situaciones conflictivas utilizando la empatía, como plantear objetivos progresivamente y en escalera, ..... No nos olvidemos del trabajo de dirección del coro que hace Whoopi Goldberg

2. 'Erin Brockovich' una clase magistral sobre inteligencia emocional. Como si de un manual de recursos humanos se tratase, Erin Brockovich revela secuencia tras secuencia un catálogo de ideas sobre cómo desarrollar la inteligencia emocional en el entorno laboral.

3. En busca de la felicidad, con Will Smith: Es el individuo en organizaciones humanistas la fórmula que mejor puede ayudar a que seamos más felices, tal como apunta la película. Nos habla de Resiliencia, Responsabilidad, Actitud. Con una entrevista de trabajo genial, con empatía, tomar las riendas, ingenio,...cuando además lo tenía muy difícil:

- Soy Chris Gardner. ¿Cómo está? Buenos días (estrechando la mano a los seleccionadores). He estado pensando durante media hora una historia que explique por qué estoy vestido así. Y quería inventar algo que demostrara cualidades que ustedes seguro que admiran como seriedad y diligencia, trabajo en equipo o algo así. $Y$ no se me ocurrió nada. La verdad es que me arrestaron por no pagar unas multas de estacionamiento y vine corriendo desde la estación de policía.

- ¿Qué hacia antes de ser arrestado?

- Estaba pintando mi piso.

- ¿Ya está seca la pintura?

- Eso espero. 
- Parece que fue el mejor de su clase en la escuela secundaria. ¿Entre cuántos alumnos?

- Doce. Era un pueblo pequeño. Pero también fui el mejor de mi clase en la Armada, éramos veinte. ¿Puedo decir algo? Soy el tipo de persona que si no sabe una respuesta le diré que no la sé. Pero le apuesto a que sé como encontrarla y que la encontraré. ¿Le parece justo?

- Chris, ¿qué diría si alguien se presenta sin camisa en una entrevista y yo lo contratara, qué diría?

- Seguro que traía unos bonitos pantalones.

Y todo ello con actitud positiva ante la vida, espíritu deportivo para superar dificultades y fracasos, valorar lo que se tiene sin compararse con los demás y, sobre todo, tener en cuenta a las personas

4. Y "Gladiator" La utilización de la película (y de la música) que hizo Guardiola, entrenador del Barcelona antes de la final de Roma se basa en la idea de que el ambiente de trabajo es muy importante para los resultados (42 por ciento). El auténtico liderazgo (como el de Pep Guardiola) genera un clima de satisfacción, rendimiento y desarrollo. "Cuando las cosas van mal, jamás les grito. Jamás. Les grito cuando ganamos 4-0. Cuando perdemos, jamás les grito, porque si perdemos hay razones, y ellos sufren porque lo quieren hacer bien. Quieren sacar las cosas adelante $y$, como les entiendo, intento generar soluciones para que puedan jugar mejor". Liderazgo Guardiola 

cine:

\section{UNAS PALOMITAS para acompañar estos ratos de cine y hacer más fácil el TRABAJO EN EQUIPO:}

Unir sentimientos es la esencia de un equipo. Añadir a lo técnico un plus emocional, no sólo es más agradable, sino también más rentable.

Un equipo en "sinergia efectiva es aquel que tiene las siguientes polaridades emocionales:

1. Está Cohesionado alrededor de un liderazgo (pueden ser una o más personas, siendo que cuanta más sean mejor será la cohesión).

2. Con alta autoestima en su quehacer profesional.

3. Cooperando con el resto de los compañeros.

4. Ilusionados por lograr metas.

Equipos predominantes en sinergia de mantenimiento pueden fallar en uno o varios de los puntos señalados.Su productividad será mínima si están:

- Disgregados

- Con baja o nula autoestima

- Compitiendo entre ellos

- Desazonados o claramente desesperanzados en relación a las metas que persiguen.

Equipo en sinergia efectiva. El equipo está cohesionado, en cooperación, con autoestima y cohesionado. Las personas tendrán sentimiento de mutuo respeto, confianza, orgullo de pertenecer a este equipo y por el trabajo realizado se sentirán animosos de cara al futuro.

\section{El Peligro de esta posición:}

1. Cansancio del núcleo que lidera el equipo

2. Falta de proyecto que ilusione y que lleve a situar a cada miembro a sus propios objetivos egoístas

3. Pasar a competir en lugar a cooperar. 
Equipo cohesionado en posición de competitividad interpersonal: Hay competitividad entre la mayoría de sus miembros.

\section{Peligro:}

- El problema de este equipo es que no sabe combinar las ambiciones de sus miembros

- Puede que incluso se critiquen entre ellos e

- Incluso que se pongan zancadillas.

Equipo cohesionado pero carente de ilusión: no hay competitividad sino más bien una desesperanza aprendida. Es un equipo que puede funcionar bien porque sus miembros mantienen una buena autoestima. $Y$ orgullo por hacer bien el trabajo., también por el hecho de que en la base existe un respeto interpersonal. Pueden que no esperen ya nada de su empresa y puede que hayan sido engañados reiteradamente.

Oportunidades En todo caso un líder que pretenda sacarles de la rutina, deberá apelar más a grandes grandes proyectos que serán analizados desde el escepticismo,

Equipo disgregado pero con buena sintonía personal: Estamos ante un equipo en el que van a predominar descaradamente las normas de compadreo. "campar cada uno por su lado haciendo lo mínimo" Los miembros de este equipo pueden ser que hasta se lo pasen bien porque una parte de la energía se desviarán a juegos sociales.

Oportunidades Hay que crear nuevos retos colectivos con sensación de ganancia. Máxima eficacia de esta táctica si se acompaña de cierto riesgo personal.

Un equipo enfermo tiene estas características:

- No tiene un objetivo común

- sus miembros no disponen de metas concretas

- No tienen un sistema de consecución de objetivos

- Desconfianza entr los profesionales que forman parte del grupo

- Falta de refuerzo tras la consecución de los objetivos

- Líderes que no motivan y no dan a cada persona su importancia

- Falta de comunicación 
Un equipo sano se caracteriza por:

1. Tener un propósito claro

2. Contar con un líder que negocia con los miembros del equipo el reparto de tareas

3. El equipo lo conforman personas con conocimientos y habilidades que fomentan el intercambio y que se formen para mejorar

4. Tener un sistema de reconocimeinto y recompensa

5. EL equipo se basa en la flexibilidad y autonomía para sus integrantes

6. Existir protección contra los bloqueadores de creatividad

7. $Y$ todo tiene como elemento cemento una comunicación proactiva, basada en la credibilidad de las personas, el dialogo, la participación, la escucha, el contenido fácil, la claridad, la utilización de canales físicos y tecnológicos y la importancia de tener en cuenta que lo importante de comunicar es llegar.

Y lo que hace que un equipo funcione son:

1. La sinergia de mantenimiento, es decir, buenas relaciones interprofesionales

2. SINERGIA EFECTIVA, basada en dos cosas:

- que cada persona del equipo sienta que su saber ocupa lugar, que da y que recibe

- que existe un proyecto de equipo conocido por las personas del mismo, compartido en gran parte y que además ha sido objeto de la participación de las personas que lo conforman

3. Y para terminar unas dosis de comunicación y un buen liderazgo. Ingredientes para tener un equipo con emoción 


\section{AVANZAMOS Y NOS BEBEMOS ALGÚN REFRESCO:}

ALGUNAS CLAVES para llevar el equipo a la excelencia:

\section{Planificar}

2. Normas

3. Equilibrio trabajo-descanso-familia-..

4. Comunicación

5. Reacción ante la adversidad

6. Tomar decisiones

7. Personas

\section{ALGUNOS COMENTARIOS SOBRE CADA UNO DE ESTOS PUNTOS:}

1. Planificar adecuadamente las actividades es uno de los factores más importantes del trabajo en grupo. Cada uno de los integrantes debe conocer perfectamente sus funciones dentro del equipo.

2. Establecer normas básicas de grupo que vayan más allá de los puramente técnico. El respeto por los compañeros, por la competencia, por el objetivo, así como la confianza y la generosidad entre los miembros son aspectos fundamentales.

3. Mantener un equilibrio que permita trabajar, descansar y disfrutar del tiempo de ocio es importante para que las cosas funcionen dentro de un equipo. Convertir el sacrificio en diversión.

4. Comunicación. En todo grupo debe existir una comunicación abierta y directa. Es clave que todo se pueda hablar. Es imprescindible que haya libertad para opinar y disentir.

5. Reacción ante la adversidad. Nada que venga de fuera puede afectar al equipo. Para ello, una constante puesta en común, además de alegría y motivación.

6. Tomar decisiones. El gestor del equipo debe transmitir confianza y dejar un espacio para la creatividad.

7. Personas. Trabajar con un grupo es no olvidar nunca que se trata de personas y por tanto es necesario tener en cuenta las emociones.

\section{5 frases finales para reforzar:}

1. Los profesionales de un equipo tienen que tener la impresión de que dan más de lo que reciben y eso es síntoma de salud de un equipo. 
2. Pero no basta con liderazgo, proyectos y respeto. Aún así, poco va a funcionar un equipo sino hay compromiso. Respeto y consideración hacia cada profesional, existencia de proyectos y liderazgo integrador son puntales para el desarrollo de un equipo. El capital del fondo de un equipo es el compromiso de sus miembros, el cual nunca surge porque dichas personas sean buenos y bondadosos profesionales, sino porque se ha sabido crear unjuego social en el que a cada uno de ellos le importa verse valorado postivamente y ganarse un prestigio.

3. Los proyectos son algo así como el latido cardíaco de los equipos

4. Se carece de políticas y estrategias para apoyar liderazgos integradores en el nivel más cercano al profesional de la salud.

5. La mejor estrategia para un equipo es saber hacer confluir intereses personales con los del grupo. 


\section{Se demanda que se trabaje en equipo, pero se premia lo que se consigue individualmente:}

Los expertos en organización han demostrado las excelencias del trabajo en equipo y su impacto positivo en los resultados; quizá por ello, un gran número de organizaciones se esfuerzan -en la mayoría de los casos con poco éxito- por crear una cultura basada en el aprovechamiento de las capacidades de los individuos trabajando en interacción.

"Dime de lo que presumes y te diré de lo que careces", dice el refrán y algo así pasa con el tan manido trabajo en equipo; es más lo que se dice que se hace, que lo que realmente se hace y las causas, en un gran número de casos, residen en el propio sistema de medición del rendimiento de la organización, en la propia cultura organizativa.

Todo el mundo dice que trabajar en equipo es muy importante porque se generan sinergias y mejores resultados, que trabajar en equipo es una competencia esencial para poder entrar en su compañía, que si no se trabaja en equipo no se puede mejorar, etc. Sin embargo, la cuestión que deberíamos plantearnos sería ciestá realmente nuestro sistema de apreciación diseñado para fomentar realmente el trabajo en equipo?

Se demanda que se trabaje en equipo, pero se premia lo que se consigue individualmente. En no pocas ocasiones, los sistemas de compensación y promoción sólo premian lo tangible y tradicional; es decir, los resultados de ventas o productividad, sin entrar a apreciar siquiera quién o quiénes otros han colaborado en la consecución de unos objetivos excesivamente, valga la redundancia, "objetivos".

Stephen Covey relata como en una ocasión un director general de una compañía le llamó muy preocupado porque sus directivos eran muy egoístas y no colaboraban entre sí. "sencillamente, no quieren cooperar, podríamos producir mucho más si trabajásemos en equipo y 
colaborásemos" decía el director. La pregunta que hicieron al director fue: “¿cuál es la recompensa por no cooperar?" No existe ninguna recompensa por no cooperar; las recompensa por cooperar son mucho mayores".

En una pared del despacho de aquel hombre había un cuadro cubierto por una cortina. En el cuadro había unos caballos de carrera alineados en una pista; cada uno de estos caballos tenía la cara de cada uno de los directivos y, al final de la pista había un cartel con un bello paisaje de las Bermudas. Una vez a la semana en la sesión comercial el director general reunía a todos los directivos de venta y les hablada de cooperación, les instaba a trabajar en equipo y les decía "trabajemos juntos; si lo hacemos todos ganaremos más dinero"; después retiraba la cortina del cuadro y les decía "¿quién de ustedes va a ganar el viaje a las Bermudas para él y su pareja". Este director general quería que sus equipos cooperasen y trabajasen colaborativamente, pero el sistema de recompensa estaba basado en que el éxito de un directivo suponía fracaso de los otros.

Pues bien, esto ocurre en un gran número de organizaciones que demandan incluso en su selección un perfil profesional en el que el trabajo en equipo sea característica fundamental y luego sitúan a sus profesionales en una situación de competencia interna en la que no cabe la cooperación.

Por otra parte, la mayoría de las compañías diseñan su modelo de organización pensando en la forma más eficaz para ganar el mercado y servir a sus clientes. Crean departamentos, divisiones, estructuras de soportes $y$, en un esfuerzo por conseguir una mejora de resultados, conforman unidades de negocios que, con cierta autonomía, pueden incluso llegar a competir entre ellas. Hasta aquí todo es sano, es acertado y bueno. Sin embargo, la patología comienza cuando estas unidades en su afán por parecer mejores que sus homónimas, empiezan a mostrar comportamientos negativos y disfuncionales que van en contra de las otras unidades de negocio que son parte del mismo todo empresarial.

Se forman tribus o "reinos de taifas", silos o feudos, que lejos de colaborar y ganar sinergia en pro de los resultados globales de toda la corporación, intentan encontrar sólo soluciones a sus propios problemas y destacar por encima de las demás unidades. Puede que no obtengan buenos resultados, pero que los del resto de las unidades sean peores que los de la suya, parece convertirse en el principal objetivo. 
$Y$ esto, suele ocurrir también porque los sistemas de reconocimiento y sanción o de premio y castigo que se utilizan en la mayoría de las organizaciones, lejos de disuadir estos comportamientos los fomentan. Se suele compensar en mayor medida por lo que consigue cada unidad de negocio, -incluso como antes apuntábamos por cada individuo- o por cada una de las partes aisladamente, que por lo que se consigue por toda la empresa, por el todo organizativo.

¿Cuál es el tratamiento más eficaz para combatir esta invasiva dolencia? o lo que es lo mismo, ¿qué hacer entonces para trabajar en equipo?

Respecto a su tratamiento hay dos:

1. uno médico o blando, "no haga eso, va en contra del resultado global de la empresa, aunque a usted y a su unidad le beneficie", y

2. otro quirúrgico o duro, que consiste en revisar nuestros sistemas de promoción y compensación, sin olvidar que al igual que no se puede cambiar de frutos de un árbol sin cambiar su raíz, tampoco se puede cambiar actitudes sin modificar los procedimientos. Trabajar sobre las actitudes y comportamientos equivale a arrancar las hojas del árbol, pero el fruto que dé el equipo será el mismo si la raíz sigue siendo la misma. Por ello en línea con el tratamiento un quirúrgico más agresivo, lamentablemente, como muchas veces ocurre en la misma cirugía, puede que no quede más remedio que para salvar "el todo" organizativo haya que amputar a aquel miembro o sustituir al responsable de la unidad que fomenta la independencia e impide las sinergias, mata las ideas, aborta la innovación y aniquila la interdependencia de su empresa; es decir, el que impide el trabajo en equipo.

1. ¿QUÉ SIGNIFICA COMPARTIR? Compartir es ayudar, participar, repartir. Es bueno compartir porque es una manera de dar sin esperar nada a cambio. Compartir es comunicar vivencias y deseos, miedos y alegrías. Muchas personas se hacen "individualistas" y egoístas y ya no están dispuestas al compartir. Se estiman los intereses personales e individuales y no hay disposición a la reciprocidad. Pero encontramos también personas generosas, que dan su tiempo y capacidades al servicio de los demás. A veces eso les exige sacrificios y mucho esfuerzo, pero tienen fuerza en su corazón para entregar lo mejor de sí mismos, para que los demás estén alegres y sientan un poco de felicidad. 
Por tanto son importantes los valores del COMPARTIR, de la SOLIDARIDAD, de AYUDA MUTUA y de RECIPROCIDAD.

2. ¿qué aporta hacer un favor?: Hacer favor significa regalar, dar sin esperar nada a cambio. En el momento de hacer un favor o ayudar a alguien se está compartiendo, la ayuda mutua es importante porque no solo se debe recibir sino también hay que dar y de esa forma estaremos practicando el valor del compartir.

3. ¿Y en donde se demuestra el compartir y hacer favores? Se demuestra en la amistad. La amistad es dar y recibir, sin esperar nada a cambio. El valor de la amistad es saber agradar y compartir. Pero hay que tener en cuenta que para "tener" hay que "compartir". Si un niño comparte tanto sus objetos personales como sus ideas, es probable que el resto del grupo lo catalogue como una persona generosa y comprensiva y no querrán dejarlo de lado. Compartir significa un acto generoso y solidario para con el otro, en el que uno debe desprenderse de algo, que muchas veces cuesta, para dárselo de manera desinteresada a otro compañero. Una buena idea para que el niño explore el valor de esa palabra es enseñarle que debe prestar sus juguetes, sus libros, compartir con otros niños su merienda o sus chuches.

¿Y en los equipos sabemos compartir y hacer favores?

Leí hace poco un artículo que habla de las 8 peores frases que puede usar un jefe cuando se dirige a un empleado. Expresiones que además de sumar estrés, menoscaban la dignidad de cada trabajador.

- No te pago para pensar Un jefe que maneja a su equipo bajo el concepto de "te pago para que hagas lo que ordeno y nada más" pronto tendrá un equipo desmoralizado y hará que sus mejores trabajadores sientan que el empleo les quedó chico para sus capacidades.

o No quiero verte en Facebook / Twitter mientras estés trabajando

o Lo tendré en consideración Un jefe que usa esta frase cuando interactúa con sus empleados, les está diciendo implícitamente que no le importa lo que piensen.

o ¿Quién te dio permiso para hacer eso?

o iDeja todo y haz esto AHORA!

o No me vengas con problemas: tráeme soluciones 
o Tengo varias críticas sobre ti... y aquí todo el mundo piensa lo mismo Un verdadero líder debe resolver los conflictos de forma regular, y no refugiarse en el supuesto apoyo de los demás para hacer una crítica que debiera tener sustento por sí misma.

o Deberías sentirte afortunado de tener un trabajo 


\section{PASAMOS A LOS POSTRES, doble en este caso: jefes y comunicación}

'Pepu' Hernández que fue entrenador de la selección española de baloncesto y consiguió llegar a su equipo a lo más alto del campeonato del mundo, mezcló emoción y confianza para alcanzar el triunfo, poniendo al equipo por encima de los individualismos y considerando estrellas a todos sus jugadores. Su idea de entrenador es la de director del grupo, que da "facilidades para que surjan las emociones", buscando la cohesión, así como la autogestión que hay que gestionar, con unas líneas de trabajo, con sugerencias al grupo y con la puesta en común de las ideas de todos.

En su manual de gestión, reinan tres palabras:

- respeto ("el respeto no tiene que ser básicamente hacia la jerarquía, sino hacia los compañeros, los objetivos, los...". )

- compromiso ("todos ayudan en las tareas de todos") y

- confianza ("la confianza para poder hablar y decir lo que se piensa; cuando no existe esta confianza es cuando empiezan los problemas"), conceptos que guiaron al equipo a ganar el Mundial.

Para él, "todos los jugadores tienen que sentirse importantes, todos los miembros de mi equipo son estrellas porque tienen talento deportivo y personalidad, y eso es una garantía, al igual que saber que pueden colaborar y ayudarse cuando se necesite". Y lo que llevó al equipo español a lo más alto del podio fue "la unión y la amistad de los jugadores, que les hizo llegar a una química especial", que es la base para una sinergia de mantenimiento de cualquier grupo, ya que como dice Pepu «es importante trabajar para que el equipo esté más unido en las relaciones personales, que en las tácticas». Y además para conseguir el éxito sabían que si el equipo pierde, ellos individualmente también pierden y que todos "se sientan unidos y sepan lo importantes que son todos, y no sólo uno o dos".

Por tanto, un equipo ganador se crea a base de:

- Gestionar bien las personalidades del equipo.

- Trabajar habilidades sociales para comunicarse con las personas de su equipo y poderles sacar un plus de esfuerzo.

- Escuchar y valorar las aportaciones de los miembros del equipo. 
- Analizar en positivo las críticas y sacar aprendizaje de los errores.

- Hacer participes a todos del éxito

- Moderar los egoismos y hacer cosas para ganarse las voluntades del equipo

Cuando acabe el partido, quiero que podáis tener la cabeza bien alta, y yo sé que sólo hay una manera de que esto sea así y es que sepáis que habéis hecho todo lo mejor que podéis por vosotros y por vuestros compañeros,....Lo mejor es no poder hacer más"

El líder es el mejor de los servidores, es capaz de apoyar iniciativas, es transmisor de protagonismo(protagonismo va unido al reconocimiento y debe existir un equilibrio entre protagonismo y reconocimiento)

El líder debe ser EDUCADOR

Un LÍDER puede o no ser jefe. Un jefe puede o no ser LÍDER

Un LÍDER debe ser un FORMADOR DE LÍDERES, haciendo buen uso de la libertad, asumiendo riesgos y no eludiendo la responsabilidad.

El liderazgo no debe de ser estático, es dinámico, se construye día a día, es como una nube que va cambiando y depende de muchos factores, de las tareas, de los momentos y de las personas.

El equilibrio de un equipo depende de la relación entre sus miembros y de las funciones que desempeñan cada uno de ellos. El equipo se proyecta en cada uno de sus integrantes.

La implicación del individuo, la cohesión del grupo y el sentir el equipo como algo propio garantizan gran parte del éxito. La máxima aportación de cada individuo a su equipo, el máximo rendimiento, siempre dependerá de que cada uno de nosotros tengamos la oportunidad de crear, decidir, actuar y asumir responsabilidades. Hay que responsabilizar a todo el mundo para que cada uno aporte cosas y añada valor al equipo. El protagonismo corresponde a cada uno y para ello hay que romper con la rutina habitual. Y para ello hay que trabajar en el 
ámbito técnico, buscando talentos y en el ámbito emocional, favoreciendo actitudes al contarle al profesional qué se espera de él/élla.

Las actitudes y las aptitudes que deben rodear a la figura del líder, tienen que estar enfocadas, necesariamente, hacia el beneficio del equipo y su máximo desarrollo como tal. Las organizaciones hiperlideradas no permiten que la gente aporte la parte de sentimientos de propiedad de cada uno.

La primera misión de un líder es prestar su mejor disposición para conseguir el máximo rendimiento de toda su gente. Y no sólo eso: un líder ha de crear, a su vez, personas con capacidad de liderar.

Un líder debe estar dispuesto a ceder en beneficio del equipo, transformando parcelas individuales en parcelas colectivas, trabajando infatigablemente en la sombra para el bien del grupo. De todas formas es importante reconocer que lo que hace un líder afecta a la gente del equipo y ello afecta a los clientes y por tanto a la sociedad.

Un equipo eficaz es aquel que sigue funcionando a la perfección, aún en ausencia temporal del líder. No se debe olvidar la importancia que tiene el individuo dentro de un equipo. Cada individuo posee unos valores que deben ser aprovechados por su importancia para conseguir equipos eficaces, ya que, sin ellos, esto sería imposible.

La Implicación y el Sentido de Propiedad son otras dos características importantísimas en la definición del equipo. Un equipo también se mantiene vivo por elementos de motivación, buscando el sentido a las cosas y eso se consigue cambiando las pequeñas cosas que permitan adecuarnos y a veces cambiando para encontrar los elementos de motivación.

\section{UN LÍDER DEBE TENER VISIÓN DE JUEGO Y ELLO AYUDA A DISFRUTAR Y A UNIRSE HACIA UN OBJETIVO COMÚN}

De líder a líderes: Cooperación y gestión de las emociones ingredientes básicos en la mejora de un equipo

Es necesario avanzar hacia un nuevo modelo en el que las emociones y su gestión sean la piedra angular de las organizaciones. Basta de líderes 
absolutos, que tienen todas las respuestas y donde el equipo se mueve en función de lo que "manda" el jefe (normalmente hombre).

Es la era de la colaboración, donde quien manda, quien ejerce de líder debe tener humildad y respeto, confianza y apoyo, tranquilidad y seguridad. No todo el futuro de un equipo o de una organización debe escribirse a partir del dictado de una persona: los líderes no tienen ni deben tener necesariamente todas las repuestas y no saben siempre adónde van o deben ir sus equipos. Necesitan el concurso de todas las personas del equipo para conseguir el éxito Las soluciones vienen y vendrán de la cooperación, del trabajo de muchos, de la colaboración, de los liderazgos. Y este clima de colaboración y ayuda facilita el desempeño del trabajo frente a lo que hacen algunos que destruyen la innovación y propician un clima que desmotiva y desmoraliza. Es importante decirles a estos jefes que lo importante es que no desmotiven.

Por todo ello, es necesario una forma de liderazgo capaz de implicar emocionalmente al equipo, con actitudes colaborativas o enfoques basados en la participación del equipo, que ayudan a crear un buen ambiente laboral para que los equipos funcionen mejor.

El líder ha de gestionar a su equipo ilusionándole y animándole a un esfuerzo común, partiendo del ganar-ganar., siendo la confianza el lubrificante necesario para que la relación funcione de forma adecuada. El liderazgo basado en la cooperación obtiene unos excelentes al conseguir una buena y deseable confianza con y en el equipo con la idea de fondo de que si tú das lo mejor de ti y el ambiente es propicio y favorable, los demás harán lo mismo, pero si el entorno es disfuncional y contaminante, las emociones se contagian y se pervierte el sistema. Todos los estudios apuntan que lo que más influye en el compromiso y la motivación de las personas es la figura del/a jefe/a. Este/a jefe/a que suma ayuda a generar redes de confianza basadas en el diálogo y la colaboración, con mayor satisfacción, felicidad y compromiso y mejores resultados. Estar más feliz y a gusto con uno mismo, con las relaciones personales funcionando en el equipo y un proyecto compartido facilita la ilusión de todos.

Un estilo humano, tranquilo e integrador moviliza voluntades, convence con razones y adhiera a su equipo desde las emociones. 


\section{Y TERMINAMOS COMUNICANDO:}

Dos películas para hablar de presentación en público y por tanto de comunicación. La presentación hace bueno el producto; por tanto es fundamental:
A. PREPARÁRSELO
B. CREÉRSELO
2 películas que utilizo en clase para mejorar habilidades de presentación en público:

1. El discurso del rey o como afrontar con éxito el miedo a hablar en público.

Pero para alcanzar una dicción casi perfecta y convertirse en uno de los mejores discursos jamás pronunciados se tuvieron que superar unas cuantas lecciones.

Por ejemplo, desnudar al Rey, liberarle de los prejuicios y dejarle ver todo el potencial que incluye su fuerte personalidad. Además, consigue transmitir confianza a su pupilo lo que contribuye a un aprendizaje cada vez más rápido.

- Otra característica que hace única el éxito del discurso del Rey en la época es que se utilizó la radio como medio novedoso.

- Liderar a un país necesitado de emociones a través de la palabra, del discurso y de la pasión contribuyó a amplificar el éxito del monarca.

2. Julio César o Marlon Brando (Marco Antonio) y su magnífico discurso.

La historia comienza tras el asesinato de Julio César, que ha caído apuñalado a manos todos sus enemigos, a quienes él consideraba amigos.

Bruto responde con el golpe fatal. Ésa inseguridad se transmite en su discurso (que también es digno d eoir y valorar), cuando lo primero que hace es mirarse las manos ensangrentadas.

Marco Antonio irrumpe con el cuerpo aún caliente del César en brazos horrorizando a la multitud, y rompiendo el efecto tranquilizador de las palabras de Bruto (una imagen vale más que mil palabras), que trata de convencer al pueblo romano con las manos aún ensangrentadas, de que todo ha sido por el propio pueblo.

Su discurso concluye precipitadamente y carece del efectismo del de Marco Antonio. Bruto permite a Marco Antonio hablar un tanto 
desconcertado y deja su discurso sin un final claro, pensando que Marco Antonio hará una elegía a César:

Marco Antonio entra en escena y le cuesta hacerse con la atención del excitado pueblo romano; por tres veces tiene que llamarles la atención para pedir la palabra. Marco Antonio empieza diciendo: Amables romanos... amigos compatriotas... y durante casi todo su discurso muestra un tono conciliador y de adhesión total tanto a los romanos como a los conspiradores.

Es muy importante para el proceso de la exposición en el que se desea persuadir a una audiencia,(importante conocerla, BÁSICO) saber adherirse estrechamente a la misma (TENER CLARO EL OBJETIVO) yadecuar el estilo al público. Marco Antonio trata de convencer al público, sin que al público o los traidores les parezca que Marco Antonio les quiere convencer de algo. En realidad, está agitando al pueblo a la rebelión contra los traidores sin que se den cuenta. Marco Antonio empieza con una pausa efectista para que termine de callar la multitud. No viene a glorificar al fallecido Julio César, que era ambicioso no porque lo crea él, sino porque lo dice el honorable Bruto. César ha muerto y no niega sus defectos: el mal que hacen los hombres les sobrevive, el bien queda frecuentemente olvidado... si fuera ambicioso era una falta grave, y gravemente ha pagado su falta... dice Marco Antonio. Constantemente hace alusiones a Bruto (COMPARA y CONTRASTA, lo cual es un buen instrumento), aunque con una fina ironía Bruto es un hombre honrado... como honrados son todos los demás. Constantemente evita contradecir a Bruto es un hombre honorable, pero por otro lado desmonta su discurso: César no era ambicioso; César trajo riqueza a Roma... lloraba cuando los pobres se lamentaban. Y no sólo eso, sino que por tres veces rehusó la corona de Roma, ¿'es eso ambición? -se pegunta Marco Antonio-. Pero de nuevo Bruto es un hombre honrado. No hablo así para desaprobar las palabras de Bruto. Dice que no quiere incitar a la ira sino a la pena ¿qué os impide llorarle?

De nuevo hace una pausa dramática (LAS PAUSAS Y LOS SILENCIOS SON BUENOS), más fingida que real, para valorar el efecto de sus palabras en la multitud, ganar tiempo para elaborar su discurso, e inspirar lástima de nuevo.

Pese a no hablar claramente, sus palabras y sus gestos están impregnados de una pasión inconfundible, y ningún orador es capaz de ganar a su público si no habla con pasión (FUNDAMENTAL: CREÉRSELO; DISFRUTAR; ...). El discurso debe vencer a la inteligencia 
del público, pero más aún a sus emociones (BÁsICO), puesto que la multitud -y eso lo olvidan casi todos los oradores- se comporta de manera emocional, no racional (HABLAR AL CORAZÓN PARA LLEGAR A LA CABEZA). La convicción del pueblo en la culpabilidad de César ha dado paso a la confusión. Mientras, Marco Antonio sigue exponiendo los hechos de una manera aparentemente distante. Utiliza un recurso escénico para centrar la atención del público, creando interés por el testamento de César y sólo desvelando una pequeña parte del mismo. Cada vez más va despertando la curiosidad de la audiencia: Cuando conozca el pueblo su testamento... aunque me reservo su lectura, el pueblo correrá a besar sus heridas. [...] no es prudente que sepáis hasta qué extremo os amó. Y continúa encendiendo al pueblo a la vez que le incita a contenerse: $y$ si os dijera que os instituye herederos, ¿qué no habría de acontecer? La respuesta es evidente, acontecería una revolución.

El pueblo ha pasado de la confusión a la ira en un proceso estudiado por Marco Antonio. Tal vez haya ido demasiado lejos al hablaros de ésto, temo agraviar a los hombres honrados cuyas espadas traspasaron al cuerpo del César. De nuevo dosifica al máximo el efecto mientras revela (IMPORTANTE IR PASO A PASO), primero las vestiduras, y luego el cadáver del César. Poco a poco va girando el sentido de su discurso y se vuelve más explícito al hablar del maldito acero de su muy amado Bruto. Palabras como saña, ingratitud, vil traición... Describe la muerte del César casi como la caída de un Dios. Pero de nuevo el dice que no quiere instigar la ira, sino la piedad (ES BUENO NO GENERAR ENEMIGOS: importante hablar para el más lejano o contarrio a las ideas de uno). Su giro dialéctico ha sido progresivo y muy sutil, casi imperceptible. Vuelve a la contradicción que ha sido el centro de todo su discurso: pero son sensatos y honorables, y no dudo que os darán razones convincentes. Razones que el propio Marco Antonio ha desmontado una por una sin mancharse su túnica romana. $Y$ utiliza sus recursos una vez más al decir: No soy orador como Bruto, yo soy, como todos sabéis, un hombre sencillo que amaba a su amigo [...] pero no tengo ni talento, ni elocuencia, ni estilo, ni ademanes, ni el poder de la oratoria que enardece a los hombres...

Además, la gente se suele fiar (IMPORTANTE DISCURSO

ESTRUCTURADO y FÁCIL DE SEGUIR PARA GENERAR CONFIANZA) más

de la gente cercana al pueblo que de los intelectuales o que ellos perciban como demasiado elitistas. Y volvemos a la adhesión: es imprescindible evitar que el oyente nos confunda con un rival o alguien 
ajeno, para convencer es necesario adherirse. Hablo llanamente y no os digo sino lo que todos conocéis -prosigue Marco Antonio- os muestro las heridas del César y les pido que hablen por mí. No hacen falta más comentarios, al menos para el pueblo de Roma que corre dispuesto a linchar a los traidores.

Es decir, que para llegar hay que generar CREDIBILIDAD, COHERENCIA, CONTENIDO FÁCIL, CLARIDAD, CONTINUIDAD, CAPACIDAD DEL OYENTE ... Así se llega y se es eficaz. Todas ellas, claves para ser un buen orador y que el mensaje llegue.

EN TODO ELLO, La mirada es uno de los elementos de comunicación no verbal más determinantes.

Las miradas que nos gustan son miradas que escuchan y preguntan, miradas que responden y asienten, miradas alegres y a veces de tristeza, miradas que confían y confiadas, miradas de silencio y de palabra, miradas concretas y con refuerzo, miradas que alimentan frente a las que echan para atrás, miradas trasparentes y sinceras, miradas realistas con ideales, miradas que ayudan o que implican, miradas que apoyan y que creen, miradas atractivas y mágicas, miradas interesantes o con deseo, miradas con atención y con acción, miradas con calidad y calidez, miradas breves y con contenido, miradas serenas y convincentes.

Y preferimos las miradas cálidas frente a frías, miradas profundas frente a superficiales. Miradas concretas frente a abstractas, miradas bidireccionales frente a las que atacan, miradas accesibles frente a distantes, miradas que defienden frente a las que atacan, miradas que hablan poco frente a las que lo dicen todo. Queremos las miradas fáciles, coherentes, firmes, seguras, respetuosas, honestas

\section{En definitiva: Miradas éticas y con valores, en definitiva miradas saludables}

Llego, me siento y lo primero que busco es su mirada Sus ojos me preguntan y mis palabras y miradas responden

Busco en el poco tiempo sus ojos y ellos me hablan en silencio, Y yo en silencio, les escucho y éllos fijan en los míos, sus palabras. Sus ojos iluminados me alumbran por momentos, 
me ayudan a sentir la esperanza

Sus ojos expresivos me oxigenan, me generan ilusión

y me dan fuerza.

Sus ojos son caricias, siento su tacto, siento su sonrisa y siento su mirada, siento su cercanía y siento su escucha Mejor dicho, me siento mejor al ver sus ojos expresivos, que dialogan con lo que siento.

$Y$ es que hay ojos que miran, hay ojos que hablan, hay ojos que ríen, hay ojos que lloran, hay ojos que escuchan, hay ojos que tocan, hay ojos que huelen, hay ojos .... Porque, SOLO en su MIRADA puedo sentir SU VOZ, SOLO en sus OJOS puedo ver lo que dice, sólo en su mirada, noto que me curo Y por eso mis OJOS reclaman SU MIRADA, PARA COMPRENDER LO QUE ME DICE

PARA ENTENDER lo que me plantea que haga y APRENDER lo que necesito

Y es que necesito sus palabras, \#palabrasquecuran necesito sus miradas para curarme, \#miradasqueescuchan

Si quieres hablar con alguien, mírale a los ojos, suavemente, con dulzura

Si son varios, mira al más distante, o al más contrario a tus ideas y nunca le ignores

Si son muchos, busca la cercanía y no te quedes sólo con una "cara gancho". 
Si al que mirar está lejos, utiliza el teléfono, poniéndole ojos con quien hables

Si es importante, visítale. Y mírale a los ojos

Si te interesa mucho, búscale y no te olvides de regalarle una mirada

Si quieres demostrar seguridad, no desvíes la mirada.

Si pasan todo el día, pon un cartel para poder ser mirado por mil ojos

Si se encuentran dispersos, haz un folleto lleno de miradas.

Si quieres que te lean, añade dibujos (con ojos de cercanía).

Si quieres que te crean, ponle una foto de tu mirada

Si quieres impresionar a todo color

Si quieres calidad, en blanco y negro

Si quieres que te entiendan, diciendo sólo tres cosas, mírale

Si quieres que te retengan, una sola y con mirada, que es la que habla.

Si quieres que te sigan, mira y acércate.

Si quieres enganchar, pregunta con la mirada

Si quieres aburrirles, no busques el color de sus ojos, no les mires.

Si quieres comunicarte, mírales.

Si quieres que te atiendan, escúchales con una mirada atenta, cercana

Si quieres que te odien, mira con indiferencia o con "miradas que matan".

Si quieres convencerles, mira con diálogo, con cercanía y con miradas que aman. 
Sin duda la salud es transmisible. Mirar, que es comunicar, es sin duda saludable. 